\section{REFLEXIONES SOBRE LA EMPRESA EN EL CONTEXTO DE LA INNOVACIÓN SOCIAL}

\author{
Luis Cañada Vicinay \\ Director y presidente de Vicinay Cadenas
}

\section{THOUGHTS ON THE ENTERPRISE AND THE CONTEXT OF SOCIAL INNOVATION}

\begin{abstract}
The present article tries to analyze the relations and connections between the discourse of social innovation and the enterprise. In this article, the author explores the discourses, actions and different forms of business management in an attempt to comprehend the philosophy and meanings that are hidden in the processes of Social Innovation. Aspects such as human sustainability, creativity, talent, knowledge, emotions, or culture play an important role in the innovative dynamics that take place inside the enterprise world, and the strategies that this one brings into practice to actualize and reinvent itself through the years. For this reason, the enterprise is not only a continuous challenge to its' own activity and for the people that work in it, it is also a representative sable of the society we live in how this one evolves and develops.
\end{abstract}

KEY WORDS: Social innovation; emotalent; knowledge; creativity; enterprise; culture.

\section{INTRODUCCIÓN}

En este trabajo el autor reflexiona sobre varios temas en los que ve interrelaciones entre la innovación social y la del mundo de la empresa.

No ha sido fácil para una persona del entorno empresarial establecer conexiones con la innovación social y no está de más el advertir que ha tenido ciertas dudas sobre la conveniencia de publicar sus reflexiones ya que de alguna manera se encuentra marcado por Ludwig Wittgenstein, de hecho acostumbra a decir que le quedó muy marcado un pensamiento recogido en su "Tractatus logico-philosophicus" cuando expone la proposición 7, en la que dice:

"de lo que no se puede hablar hay que callar" (1)

Para resolver su duda ha contactado con una amiga imaginaria a la que Ilama Forjana porque es forjadora y cade-
RESUMEN: El presente artículo trata de abordar aquellas ideas que giran en torno a las conexiones que se producen entre la innovación social y el mundo de la empresa. En él el autor explora los discursos, las acciones y las formas de gestión empresariales en un intento por comprender los sentidos y la filosofía que se esconde detrás de lo que llamamos procesos de Innovación Social. Aspectos como la sostenibilidad humana, la creatividad, el conocimiento, el talento, las emociones y la cultura juegan un papel crucial en las dinámicas innovadoras que se producen dentro del mundo de la empresa y de las estrategias que ésta emplea para reinventarse y actualizarse con el paso de los años. De este modo, la empresa no sólo acaba convirtiéndose en un desafío constante para su propia actividad y para las personas que trabajan, también se convierte en una muestra representativa de la sociedad en la que vivimos y cómo ésta se desarrolla.

PALABRAS CLAVE: Innovación social; emotalento; conocimiento; creatividad; empresa; cultura.

nera, igual que el autor, y ayudante de Hefesto, el dios de la Forja del Olimpo griego.

Forjana. Eso está bien, pero en mi opinión Wittgenstein se refiere al mundo del conocimiento no al de la especulación y lo que tu puedes hacer es especular alrededor del "cómo crees que puede ser la empresa en el contexto de la innovación social".

La especulación intelectual, así como la curiosidad, es un gran hervidero de ideas y por lo tanto un excelente caldo de cultivo de nuevas posibilidades cognitivas que pueden derivar en propuestas y/o acciones innovadoras. La especulación es un acelerador del conocimiento porque lo pone prueba y permite crear hipótesis que luego las personas o equipos que trabajen sobre ellas deberán de validar o invalidar. Así que ¿por qué no hablas de lo que sientes sobre el tema y especulas sobre tus sentimientos y emociones? 
Escuchada Forjana, el autor se anima a escribir algunas ideas y propuestas sobre los siguientes temas:

\begin{tabular}{|l|l|l|}
\hline Sociedad & Humanidad anónima & Trabajador del emotalento \\
\hline Empresa & Innovación reactiva y proactiva & Futuro de las empresas manufactureras \\
\hline Innovación & Algoritmo de sostenibilidad & GMC o Glasses Mobile Computer \\
\hline Inercia & $(\mathrm{c}+\mathrm{np}){ }^{\wedge}(\mathrm{e}+\mathrm{t})=$ ws & $\mathrm{nSMC}$ o 2,3,4,5 Sense Mobile Computer \\
\hline Vida & Frontera del conocimiento & Ágoras del emotalento \\
\hline Sostenibilidad humana & Mestizaje-Emigración & Regionalización versus globalización \\
\hline Cultura & Oportunidad versus la dificultad & Post Globalización \\
\hline Emotalento & Limites-Fronteras de lo pensable & Ecuación de la economía de la empresa \\
\hline Creatividad & Coopitalismo & 3IDRS2 \\
\hline
\end{tabular}

\section{RefLeXIOnes}

La sociedad es un término abstracto que se puede definir como el hogar donde los humanos desarrollan su vida, hogar en el que hay de todo en magnitudes numéricas ilimitadas, mejor dicho, inabarcables salvo para los conceptos numéricos a los que se tiende a reducir casi todo, asunto éste sobre el que con frecuencia algunas personas se preguntan: ¿es buena esta práctica hoy tan extendida de la cuantificación e indexación de forma que aquello que no llega a ciertos estándares no se considera?, una opinión es NO, pero aunque dicha con la boca pequeña.

En este contexto, uno de los cuasi infinitos constituyentes del todo social es la persona, tanto como individuo o como agrupación en la familia y otro es la empresa, pero a su vez la empresa no hay que considerarla como un todo, sino como un conjunto de innumerables individualidades, cada una de ellas con sus singularidades, más o menos como lo somos los humanos a título particular.

Sabemos que cada uno de los casi 7.000 millones de humanos vivos que comparten el planeta Tierra, aun siendo semejantes unos a otros, son únicos e irrepetibles y por lo tanto completamente diferenciados y lo de ser únicos e irrepetibles es así porque, son y actúan como diferentes y esa diferenciación viene porque los humanos son la consecuencia de al menos, dos herencias y diversas interacciones:

- la genética tangible y cada día mejor conocida que dice que son diferentes unos de otros con la excepción de sólo algunas personas, como es el caso por ser gemelo monovitelino, que comparten el 100\% del código genético y ello no garantiza nada ya que la activación de los genes y cromosomas es siempre diferente debido a la influencia de la proteína, y

- la cultural que se recibe del entorno social en la intangible figura de los llamados por Richard Dawkins "memes" (2), la intangibilidad de los memes tiene la propiedad de que no son observables por medios físicos directos aunque sí estudiables en función de la conducta de las personas.

Entre las interacciones que hacen de cada humano una singularidad está la propuesta de Jeremy Rifkin en el ensayo "La civilización empática" (3) donde se plantea la propuesta de que:

".........

Cada uno de nosotros es un ser extendido que vive del flujo entrópico. Nuestro yo físico se rehace a cada instante pero, de algún modo, nuestra identidad parece seguir intacta.

.........

Para los partidarios de la escuela de pensamiento de la experiencia corpórea, el hecho de que la gente tenga la sensación de que su yo es independiente del cuerpo físico no se debe a que sus procesos de pensamiento residan en un ámbito extracorpóreo. Se debe a que la persona que creemos ser está ligada estrechamente al flujo de experiencias y relaciones con los otros y esto nos da a cada uno una historia personal única. Mientras que las experiencias son corpóreas y físicas, la 'comunión' que surge de compartir 
un momento con otra persona, con otro ser vivo o con la naturaleza tiene un carácter inmaterial y pasa a formar parte de los recuerdos que conforman la historia y la identidad exclusiva de cada cual".

La empresa no es otra cosa que la asociación de varios humanos, en unas formas más o menos determinadas, con unos fines más o menos compartidos a través del desarrollo de actividades económicas.

Un fin ampliamente compartido hoy en el contexto del mundo de la empresa es el de obtener resultados económicos positivos, esto es lo que en roman paladino se dice "ganar dinero", fin que inmediatamente hay que matizar con el del destino que se asigna a los citados resultados económicos.

En función de cuál sea el destino de esos resultados, se puede estar, o no, contribuyendo al buen fin de la innovación social. La relación entre ambos aspectos en la empresa se puede canalizar a través de la cada vez más exigente cultura de Responsabilidad Social de Empresa, RSE que en una hipotética Post Globalización quizás propicie el cambio del fin compartido citado.

La innovación es un vocablo muy en boga que en los últimos años está apareciendo por doquier y con mucha frecuencia aplicándose al mundo de la empresa, casi siempre en el ámbito muy restringido de los productos que se ponen en el mercado y/o de los medios de producción, con lo que de alguna manera se pudiera estar limitando una de las ideas, concepto más bellas de las que se ha sido capaz de concebir, porque detrás de la innovación está el qué y el cómo son los humanos. Observando, que no estudiando, como son las raíces humanas, uno concluye que la naturaleza no les lleva precisamente a ser innovadores. Hay que resaltar dos planos que con mucha frecuencia se entrecruzan y mezclan sin líneas de frontera definidas, quizás porque la escala temporal entre un plano y el otro son inmensamente diferentes:

1) El primero de los citados planos es el de la inercia, ley de la física según la cual estando la cosa en estado de reposo tiende a quedarse como está, o lo que es lo mismo, el cambio de estado necesita de notable aportación de energía. Es precisamente inercia lo que ocurre en la vida y en las mutaciones que la acompañan para introducir cambios. Estos cambios y/o mutaciones no son innovaciones porque no son consecuencia de actos conscientes.

Conviene observar el vínculo de la innovación a la ejecución consciente de los actos que se realizan buscando cambios aunque la consciencia de aquéllos no esté enfocada hacia el cambio que se ha producido como pudo ser el caso del Dr. Fleming y su gran innovación con el descubrimiento de la penicilina. El referido doctor buscaba una cosa y supo encontrar en los cultivos de bacterias que le aparecieron lo que allí había, que era cosa diferente a la por él esperada, cosa que luego fue un punto de inflexión en la calidad de vida de toda la humanidad.

Hablando de la evolución de la vida, los cambios están afectados por la inercia y tienen una escala temporal de miles, quizás de millones de años para consolidarse, son casi imperceptibles para el observador humano no dotado de instrumentación externa tecnológicamente avanzada.

2) El segundo plano, cuyo horizonte temporal es muchísimo más corto y cada vez lo es más llegando pronto a lo efímero ya que si en el alba de la humanidad fue de miles o decenas de miles de años ahora puede ser de meses o años, es el de la sostenibilidad humana, sostenibilidad que está univocamente ligada a cambios constantes del entorno vital realizados de forma consciente por el ser humano, esto es, estrechamente relacionados con la cultura, o mejor aún son la propia cultura, según una acepción que el biólogo Francisco J. de Ayala y el antropólogo Camilo José Cela Conde en su ensayo compartido "la piedra que se volvió palabra - las claves evolutivas de la humanidad", dan del concepto "cultura" al asociar el término con "la modificación del medio en beneficio de uno":

"El hombre ha inaugurado una nueva forma de adaptación mucho más poderosa que la biológica: la adaptación por medio de la cultura" (2).

Entre este alcance de la definición de la cultura como la modificación del medio en beneficio de la colectividad humana y la innovación hay muy poca diferencia, de hecho se puede decir sin riesgo de equivocarse que la cultura, siempre cambiante, siempre diferente, siempre nueva, es 
una gran innovación social sostenida a lo largo del tiempo, es la innovación social por antonomasia.

Hay muchas definiciones de innovación entre las que en lugar prioritario hay que citar lo recogido en el Manual de Oslo (4) donde se crea cierto tipo de doctrina e indicadores sobre cuatro tipos de innovación: Productos, Procesos, Organización y Marketing.

De entre las definiciones de la "innovación" vamos a resaltar una que ha surgido en una empresa vasca, curiosamente la que también ha creado el personaje imaginario de Forjana. Esta empresa es de forjadores y cadeneros en ella definen la innovación como:

"la libre aplicación del emotalento por parte de las personas y/o equipos para hacer cosas diferentes que den valor a las personas, a la empresa u organización y a la sociedad" (5).

La definición merece alguna explicación, así: "emotalento" es un parasintético que se sustancia en emoción y talento, y no es banal la palabreja ya que poca innovación, poca creación, puede salir de las actividades humanas, ya sea como individuos ya como equipos, si no está la emoción de los ejecutores por detrás, pero es que además definen el talento como la conjunción del conocimiento, del saber, con la actitud de aplicarlo, de hacer cosas con él, pero no hacer cualquier cosa sino aquéllas que den valor a la persona, a la empresa y a la sociedad, siendo importante la doble condición necesaria: 1) por un lado la consciencia recogida en la definición como " la libre aplicación del...", y por otro lado, 2) que se satisfaga a los tres niveles sociales citados, dándoles valor de forma que cuando se da la conjunción de ambas condiciones en el cambio ejecutado, éste adquiere el rango de innovación.

Pero es que además hay más, el talento es moneda, es ahorro, es no despilfarro, no en vano ha sido moneda durante siglos en las culturas origen de la nuestra, la helénica y la romana. En otras palabras, se puede decir que cuando las personas aplican libremente su emotalento para hacer cosas diferentes que den valor están en el camino de la innovación.

Con frecuencia se confunde creatividad con innovación así que no está de más intentar establecer una frontera entre ambos conceptos, aunque sea difusa. Por ello es importante decir que así como la innovación no es necesariamente creación, en cuanto que puede haber innovación en la adecuada aplicación de cosas ya existentes, tampoco toda creación es inevitablemente innovación ya que para que lo sea debe de aportar valor, que es más que utilidad, a las personas que la llevan a cabo, a las empresas/organizaciones en las que aquéllas colaboran y a la sociedad en la que están inmersos. Cumpliendo estas condiciones la innovación sólo requiere que lo que se haga sea diferente a lo que se hacia anteriormente aunque ello sea práctica habitual en la comunidad de al lado o para decirlo de otra forma, el mismo hecho puede ser una innovación en un contexto humano y una rutina en otro.

Lo anterior es importante porque con frecuencia se cree que para innovar hay que estar inventando la rueda continuamente, cuando la rueda ya la inventó un anónimo artesano, posiblemente en Mesopotamia, hace unos 6-7.000 años, mientras que lo que hay que hacer es cuestionarse permanentemente cómo se emplea la rueda para ser capaces de encontrar otros usos desconocidos en la comunidad y que den valor, al margen de que sean conocidos o no por terceras comunidades. Por cierto que a veces conviene pensar si no es necesario que se rinda tributo a toda la humanidad anónima que ha puesto a disposición de las generaciones siguientes innovaciones que han traído a los humanos hasta aquí.

Ésta es una oportuna pregunta para Forjana, la que está a la vera de Zeus: ¿iOh diosa! nos podrías decir, quién fue el primer humano que dominó el fuego, el que talló la piedra, el que se agarró a un árbol caído para cruzar un río, el que se arropó, el que se calzó, el que concibió la cuña, la cuerda, la rueda, el clavo, el alfar, la siembra, el que domesticó al animal, el que fundió el metal, el que concibió el número, la escritura y así un sin fin de cosas sin las cuales no sé si hubiéramos Ilagado hasta aquí, lo que sí sé es que seriamos distintos, entre otras cosas porque las herencias de las que hablábamos antes nos hubieran configurado de manera diferente. Somos la consecuencia de la epopeya de humanos anónimos, así que nuestro tributo a todos ellos, humanos que en muchas ocasiones ni tendrían nombre propio.

F. No, no sé quienes fueron esos humanos anónimos ni dónde estaban, pero coincido en su gran importancia para 
el devenir de la humanidad, así que me sumo muy gustosa a este homenaje.

Retomando la línea argumental sobre la innovación, la persona interesada se puede acercar tanto a la innovación en general como a la social en particular desde dos aproximaciones:

1) La innovación reactiva según la cual, y trasponiendo la idea básica de Charles Darwin (6) referente a las especies que triunfan, es: "una suerte de capacidad de las personas y/u organizaciones humanas de adaptación a los cambios del entorno, cualquiera que sea éste, de forma que las hace más competitivas para subsistir".

2) La innovación proactiva, que es si no a su opuesto, sí es algo sustancialmente diferente al ser: "una suerte de capacidad de las personas y/u organizaciones de proponer cosas nuevas al medio social de tales características que fuerzan a éste a adaptarse a las nuevas posibilidades puestas a su disposición".

En el caso de la reactiva la empresa puede tener una influencia notable en la innovación social, si bien esta influencia no se visualiza necesariamente en ella, mientras que en caso de la proactiva la empresa es absolutamente necesaria para que se pueda llevar a cabo.

Como un ejemplo entre muchos otros de innovación reactiva se puede considerar el caso de cuando te das cuenta de que en tu ciudad, barrio, calle hay que derribar las barreras arquitectónicas para facilitar la accesibilidad de las personas que de una forma $u$ otra tienen movilidad disminuida, y se hace dando valor a la sociedad, en este caso no creando otros perjuicios superiores a los beneficios que se aportan y por supuesto no despilfarrando.

Es importante lo del despilfarro porque es algo a lo que desgraciadamente por esta parte del mundo se está bastante abonado, especialmente por la forma y manera en la que se emplean los fondos públicos en muchas inversiones y gastos, pero no sólo en la administración pública ya que ocurre algo parecido con la gestión de los fondos privados en organizaciones de la más variada índole, empresas, familias y personas. Aunque la observación se sale un poco del hilo de lo que se está comentando, sí se puede ayudar desde la empresa a no despilfarrar introduciendo la cultura de la austeridad, lo que en el contexto español sería una gran innovación, mientras que no sería tal innovación en algunas sociedades del mundo escandinavo como es el caso de la noruega.

Volviendo al caso, si se consiguiera derribar las barreras arquitectónicas sin despilfarro la solución sería excelente ya que se tendría un doble problema resuelto, el de la movilidad de las personas en primera derivada y otro, el del despilfarro en segunda derivada.

En el caso de la innovación proactiva se puede citar una gran serie de casos de las nuevas telecomunicaciones que son concebidas con el fin de proponer nuevas vías de interrelacionarse, de crear espacios no existentes de comunicación. Este caso es paradigmático ya que se ha conseguido crear un círculo positivo que se autoalimenta constantemente, pasando de las ideas creativas convertidas en innovaciones tecnológicas que la empresa pone a disposición de la sociedad, a las ideas creativas que devuelve la sociedad, presentando nuevas posibilidades inexploradas, por no pre existentes, y que si de vuelta, en una especie de juego de ping pong, le son ofrecidas a la sociedad con razonable funcionalidad, van a crear nuevos entornos sociales.

Ésta es la revolución de las casi ilimitadas oportunidades de comunicación a la que hoy la humanidad está asistiendo una vez más sin darse totalmente cuenta, algo que anteriormente ya ocurrió, si bien en otra escala, con la escritura, la imprenta, la incorporación de las energías inanimadas, la electricidad, el telégrafo, el teléfono, el tren, el automóvil, el avión, etc., oportunidades que propician nuevos cambios en la profundización del "yo" y sus relaciones con los "otros" y con ellas el engrandecimiento de la cultura, generando nuevas posibilidades de memes que la enriquecen a la vez que introducen algunos riesgos sobre los que conviene reflexionar, aunque quizás no sea éste el lugar para ello, pero sí para citarlos. Los riesgos más importantes se pueden agrupar en los dos siguientes: 1) el de introducir más diferenciaciones entre las sociedades del primer mundo y las de los países pre-emergentes, y 2) que las facilidades tecnológicas que pone la empresa a disposición de la sociedad propicien la uniformidad de ésta, yendo contra uno de los aspectos más significativos del ser humano, su singularidad. Para conseguir esta uniformidad los expertos de marketing hacen convivir casi 
a diario a los ciudadanos con una repetición del mito de Eva y la manzana (7) al bombardearlos continuamente con promesas de paraísos terrenales y emocionales a cambio de bienes que en la mayoria de las ocasiones son fútiles. Ciertamente hay aspectos en los que los humanos no han cambiado desde que tienen recuerdos comunes.

\section{Una propuesta en forma de algoritmo para sintetizar la sostenibilidad de la empresa}

La sombra de Einstein es alargada y así como se pone en su boca la reflexión de: "hacer las cosas lo más simples posibles, que no simplistas" y que él cuando sintetizaba su visión del universo lo hacía con el algoritmo patrimonio cultural de la humanidad "e $=\mathrm{mc}^{\wedge}{ }^{2 "}$, tratando de emular desde la distancia a Einstein, en este trabajo se propone que la innovación, y quizás más que la innovación, la sostenibilidad de las empresas se puede sintetizar en el algoritmo:

$$
\begin{aligned}
& (c p+n p)^{\wedge}(e+t)=\text { ws } \rightarrow(\text { customer people }+ \\
& + \text { net people })^{\wedge(\text { emotion+talent) }}=\text { wise solution }
\end{aligned}
$$

que en castellano cervantino quiere decir:

"las personas del cliente más la red de personas de la empresa elevadas a sus emociones y talento siempre dan con la solución sabia".

Ecuación que aplicada a la sociedad pudiera ser " $(p s+r p)^{\wedge}(e+t)=v s^{\prime \prime}$ donde ps = Personas de la Sociedad, $r p=$ Red de Personas de la Empresa, $(e+t)=$ emoción + talento y vs = Valor para la Sociedad.

Obviamente la formulación no es para ser cuantificada ya que hay varios elementos de la misma que no son discretizables, pero sí es válida para entender simbólicamente la potencia de la capacidad humana para acometer proyectos que muevan los cimientos de cualquier estructura por sólida que parezca, cuando se fundamentan en las personas, sus emociones y su talento.

Analizando con cierto detenimiento cada concepto del referido algoritmo se percibe que se habla de cosas muy en el límite como: sabiduría, talento, emoción, red, personas, solución, etc., por lo que esta síntesis habla de temas muy complejos y quizás hasta críticos, esto es que para hacer innovación sostenible, ya sea social y/o empresarial, es muy conveniente vivir en lo que se podría decir la frontera, pero no en cualquier frontera sino "en la frontera del conocimiento humano del campo del saber en el que se desarrollan las actividades".

No es extraño encontrarse con experiencias dentro del mundo empresarial, es que las personas que participan en las empresas, y por extensión las empresas mismas, son conscientes de que si quieren ser sostenibles deben de tener la actitud de vivir en la frontera sabiendo ello es sumamente difícil debido a que los bordes son siempre inestables, inseguros, de gran riesgo, complejos e inciertos y con frecuencia incomprendidos, ya que habitualmente ubicarse en ellos no es bien visto por algunos analistas, especialmente los más ortodoxos, ya sean del mundo empresarial, ya del mundo financiero, ya de la administración. Son precisamente estos analistas los que con frecuencia cualifican a las empresas y sus modos de hacer, de hecho se puede afirmar sin riesgo de equivocarse que a la frontera se la tiene miedo porque es heterodoxa. Pero no sólo hay analistas que lo ven mal, también hay empresarios e inversores que opinan igual porque hay una cultura muy arraigada de correr el mínimo riesgo, de hacer lo que, en jerga algo despectiva, se dice: "experimentos con gaseosa", lo que no deja de ser una contradicción ya que ser empresario, si algo significa, es saber y querer convivir con el riesgo.

Vivir en la frontera es ubicarse en los cruces de caminos por donde transitan todo tipo de personas, ideas, culturas, éticas, actitudes y como la humana es una especie social, la frontera propicia el mestizaje de todo tipo y condición siendo aquí donde surge la pregunta: "¿es eso bueno si a lo mestizo se le tiene miedo, pánico?", pregunta que surge entre otras cosas porque el mestizaje tiende a romper el equilibrio interior, ya sea como personas, empresa o sociedad.

El mestizaje exige hacer un hueco al o a lo diferente, y normalmente a esto no es sencillo decir que sí, especialmente si esta frontera integra la emigración y el emigrante. Nadie duda de que el trato que se de a la emigración va a ser fundamental en los próximos decenios para el equilibrio, siempre inestable por cierto, de la economía y geopolítica. Los países del llamado primer mundo están en la obligación de hacer un ejercicio honesto de reconocer a los emigrantes, sin hipocresía ni eufemismos, los derechos 
que les corresponden. Los emigrantes de hoy no son los "Ilotas" de la Esparta de la época Helénica, son ciudadanos de pleno derecho y así les debe de ser reconocido. Cómo se consigue eso se sabe, especialmente en esta época de crisis en la que desde muchos lugares, incluidos los políticos se aviva el fuego de la xenofobia y emigrantefobia, lo que sí se sabe es que hay que llegar a ello y mejor antes que tarde. El hogar humano debe de ser abierto en el sentido de la "sociedad abierta" de Kart Popper (08) y para ello es condición necesaria, aunque no suficiente, el trato justo a la emigración y al emigrante.

Como la frontera es heterodoxa no es fácil, por ello son muy elevados los riesgos de que terceros opuestos a ella puedan imponer un golpe súbito que lleve a las personas del poder disfrutar de todas las ventajas que ofrece una sociedad abierta, a todas las calamidades y penurias de una sociedad cerrada (08). Éste es uno de los grandes problemas de las situaciones, cuales quiera que sean, fronterizas.

En esta frontera está todo por hacer y explorar, no hay caminos ni señales, por ello en el mundo empresarial, es necesario disponer empresas tractoras que vayan abriendo caminos, que hagan suyas las palabras universales del artesano de la palabra que fue Antonio Machado:

"Caminante, son tus huellas el camino y nada más; Caminante, no hay camino, se hace camino al andar". (09)

La habilidad de las personas y de las empresas puede estar en aprovechar estas oportunidades para crear una corriente positiva de valor empresarial y por extensión social, que además de conseguir unas condiciones dignas de vida permitan asegurar el trabajo para los ciudadanos, lo cual no es fácil en nuestro contexto social habida cuenta de nuestra más que mejorable cultura social frente al mundo del trabajo, del empresariado y por extensión de la responsabilidad social.

Contemporáneo de Machado fue Wittgenstein quien encargaba a la filosofía las dos siguientes tareas:

4114 La filosofía debe de limitar lo pensable y con ello lo impensable.

Debe de delimitar desde dentro lo impensable por medio de lo pensable. (1)
Si las personas van de paseo con Machado a la vez agrandan los lindes de lo pensable con Wittgenstein, con toda certeza se irán aumentando las posibilidades de aportar propuestas que supongan innovaciones para cualquiera de los entornos en los que esas personas desarrollen sus actividades.

Wittgenstein plantea la filosofía como los límites de lo pensable, y ello es sumamente importante tanto en la vida de la persona, como de la empresa o de la sociedad, ya que con frecuencia la comodidad y el nihilismo van ganando posiciones y tanto como éstas ganan se van reduciendo los límites-las fronteras del pensamiento, lo que a su vez reduce la capacidad de innovación y creación dejando estas funciones a terceras personas, empresas o sociedades que paulatinamente van colonizando los espacios abandonados por las personas y haciendo de éstas una especie de muñecos al servicio de aquéllas, eso sí, haciéndolas creer que son ellas las que deciden. Cuando se es consciente de ello, a las personas no les queda otra solución que elegir entre la opción de trabajar para cuestionarse cualquier proposición que trate de limitar sus pensamientos, su imaginación, sus sueños si quieren seguir siendo ellas mismas o la de dejar que sean otros los que elijan por ellas.

Hay que soñar, hay que romper y ensanchar los límites, las fronteras de lo pensable. Hay grandes cosas y expectativas a la espera de quienes se adentren en lo desconocido. Un ejemplo sobre este asunto que se entresaca de la lectura de "Relojes de Einstein y mapas de Poincarré" de Peter Galison (10). Herry Poincaré, falleció en 1912 mientras que Albert Einstein en el 1955 y Ludwig Wittgenstein en el 1951, asi que fueron contemporáneos entre 1900 y 1912. Para 1900 Poincaré ya tenía todos los desarrollos matemáticos que le hubieran permitido poder presentar la teoría de relatividad, pero no lo supo ni pudo hacer, porque su mente tenía unos límites de pensamiento que le constreñian impidiéndole aceptar lo que la nueva teoría suponía, entre otras cosas, porque debía de romper con todo su constructo respecto a la ciencia física.

En 1905 un joven de 25 años que piensa diferente, que no tiene límites en su imaginación, escribe con frescura la consecuencia de los pensamientos a los que ha llegado, posiblemente, sin tener conocimiento de los trabajos de Poincaré, y revoluciona el mundo de la física y de la filo- 
sofía, es Einstein, que presenta la "teoría de la relatividad especial".

En 1914 da comienzo, por la estupidez de los políticos centroeuropeos en la compresión del avispero de los Balcanes, la primera gran guerra, guerra en la que uno de los forzados y esforzados combatientes es Ludwig Wittgenstein, quien además de combatiente es filósofo y aprovecha su tiempo de las trincheras para poner en orden su tratado lógico del conocimiento el "Tractatus logico-philosophicus", reflexión que leída con la perspectiva de casi un siglo, sugiere que detrás de su afirmación de que "la filosofía es el límite de lo pensable" está el análisis de que, entre los limites del pensamiento de Poincaré y los límites del pensamiento de Einstein, se encuentra el tesoro de "la teoría de la relatividad", lo que es realmente fascinante por las impresionantes posibilidades que ofrece esta proposición de escasas 8 palabras con 33 letras en la traducción castellana, si se aplican a lo que son y hacen los humanos.

Por cierto, que cada vez son más las empresas que han optado por la estrategia de cuestionarse continuamente los límites de lo pensable en el mundo que les afecta, lo que según creo las hace más sostenibles. Una lección a tener en consideración es que no hay que dar nada por supuesto ni por permanente, tanto en la empresa como en la sociedad.

Un buen ejercicio de la reflexión alrededor de los límites de lo pensable se puede hacer sobre el Capitalismo toda vez que ha estado cerca del colapso después de la crisis del 2008. Crisis que llevó a una opinión prácticamente unánime de que el capitalismo tal y como era en esas fechas había llegado a su fin y deberia de ser sustituido por algo diferente. Pues bien, si el capitalismo se debe de reformar quizás sea el tiempo de que surja una nueva figura a la que se la pueda denominar como "Coopitalismo", que no es otra cosa que el parasintético de Cooperativismo y Capitalismo. Y ¿por qué Coopitalismo?, pues porque aun siendo que el Capitalismo es conceptualmente bueno, tiene algunos aspectos que se han descontrolado y no precisamente en la dirección que da mayor valor a la sociedad, así que parece conveniente un cambio de rumbo y ese cambio se puede propiciar aportándole una experiencia ampliamente arraigada desde mediados del pasado siglo en el País Vasco, especialmente en Guipúzcoa, gracias al impulso del padre José María Arizmendiarrieta, donde en poco más de medio siglo ha enraizado una po- tente manera de hacer empresa y crear riqueza, forma que consiste en que las personas que trabajan en las empresas sean a su vez propietarios financieros de las mismas.

Cada vez son más los que piensan que en la conjunción de las dos vías, que no es otra cosa que en las empresas el capital financiero al uso, aprenda a compartir sus responsabilidades y propiedad con las aportaciones del emotalento de las personas que trabajan en el proyecto empresarial, siempre que asi lo quieran. Posiblemente ésta es una de las vías para asegurar la sostenibilidad de muchas empresas en esta parte del mundo a la vez que más acorde con el valor que aportan las personas a los proyectos empresariales, ya que cada vez con más frecuencia esta aportación es más importante y relevante que la financiera. Si ello ocurriera se puede pensar con razonable certeza que se dará lugar a una corriente de opinión y de actitud para conseguir una mayor implicación del máximo número de personas en los proyectos empresariales, con lo que la derivada primera casi segura, será una mejora muy notable del grado de compromiso de las personas de los proyectos empresariales y como consecuencia de ello un aumento, si cabe mayor, del valor que los citados proyectos empresariales revierten a la sociedad.

Posiblemente haya varias condiciones necesarias para que el "Coopitalismo" tenga un alcance y extensión masiva, la principal es que se contemple un rediseño del reparto del "poder", con más poder para las personas: el llamado "empoderamiento" y ello será más fácil, más ágil si se incorpora ampliamente el concepto de trabajador del conocimiento, o mejor el de "trabajador del emotalento" por las razones ya mencionadas a cuyo amparo no está de más reivindicar que adquieran este título no sólo los trabajadores de bata blanca sino también los que tocan producto, los que sudan y se manchan la manos. Cuantas más personas de este colectivo se sumen al emotalento mayor será la capacidad de creación e innovación de sus sociedades, más se adelantarán a las necesidades y por lo tanto menos problemas de cualquier índole tendrán como personas, empresas, comunidad y como humanidad.

En tiempos de cambio en la concepción de la empresa como el presente, las bases conceptuales de la empresa deben de someterse a una pulsión de energía que le ayude a romper los moldes que la atenazan. La empresa de hoy se basa en el "capital financiero" como principal agente, pero no ha sido siempre así y posiblemente no lo será. 
Hasta la Revolución Industrial del siglo XIX el principal agente era el "dominio de la tierra", de ella surgía el alimento para abastecer a la población, la madera para energía y mil y un usos como vivienda, utillajes y herramientas, maquinaria para la industria textil entre otras, vehículos, navíos, energía en forma de carbón vegetal, etc., y la minería para su transformación en bienes mediante la aplicación de determinadas tecnologías.

Con la aplicación masiva de la fuente de energía contenida en el carbón mineral a través de la máquina de vapor, su aplicabilidad a los ferrocarriles, a las industrias del acero, naval y la aparición de nuevos medios de telecomunicaciones, como es el caso del telégrafo, el teléfono y la radio, así como las infraestructuras para la naciente producción y distribución de la electricidad, y por último a la producción masiva del automóvil, el factor "tierra" decayó y cedió paso al factor "capital" que desde entonces avanza a velocidad de vértigo quedando prácticamente como factor monopolista en la concepción del mundo económico como base del mundo empresarial durante todo el siglo XX.

Sin embargo ya en el último cuarto del citado siglo y al amparo del impresionante auge de las industrias del automóvil, de la informática y de las telecomunicaciones tanto inalámbricas como las canalizadas a través de la red de redes, se ha propiciado la aparición del mundo de las redes sociales del que ahora sería inconcebible no disponer, especialmente para la última generación, emergiendo un nuevo factor que no es otro que el del "emotalento" de las personas, que son al fin y al cabo las que crean el valor que ponen las empresas en el mercado.

Por primera vez se ha producido el hecho de que tanto el empresario capitalista como la persona poseedora de emotalento se dan cuenta y es que el emotalento puede viajar allá a donde vaya la persona y que este hecho es, 0 puede ser, clave para el futuro de las empresas. Lo anterior ha empezado a tener tal capacidad de cambio que muchos capitalistas y empresarios están llegando a la conclusión de que la sostenibilidad de las empresas pasa por hacerse cada vez más atractivas a los trabajadores del emotalento, empresas que toman conciencia de que las que no lo sean, no podrán gozar de la colaboración de las personas que les serán necesarias para llevar a buen puerto sus proyectos. Aquí está una de las claves del cambio de paradigma en las relaciones laborales. El algoritmo $(\mathbf{c p}+n p)^{(\mathfrak{c}+t)}=$ ws funciona.

Si fueron necesarios del orden de 200 años, 1780-1980, para que el factor "capital" se hiciera con la inmensa mayoría de la importancia en la concepción de la propiedad del mundo empresarial, es posible que no lleguen a 100 años, para que el "capital" sea sustituido por el "emotalento" como factor dominante en la propiedad y por tanto en la administración del poder de las empresas.

A nadie se le debe de escapar que el concepto de "Trabajador del Emotalento" y el debate a su alrededor será fascinante, porque va a abrir innumerables foros sociales sobre las funciones de unos y otros, esto sobre el rol de los otrora llamados patrón y trabajadores y no digamos nada sobre el futuro que les espera a los sindicatos. Todos van a tener que someterse a un profundo proceso de aggiornamento o lo que es lo mismo, todos van a tener que someterse a la pulsión de energía que les desprenda las cáscaras rigidizadoras para convertirse en unos "entes" nuevos. Va a ser interesantísimo.

Al amparo del "Trabajador del Emotalento" no está de más el pensar sobre cuál puede ser el futuro de las empresas industriales manufactureras. Una propuesta es que en ellas será necesario que todos sus trabajadores tengan el rango de "Trabajador del Emotalento" lo que requerirá que se automaticen hasta límites hoy insospechados. Ninguna máquina necesitará de persona presencial aunque sí de persona que la atienda. Esto ya es importantísimo porque por un lado no habrá puesto de trabajo que sea inaccesible a la mujer 0 a personas que pudieran tener alguna limitación del tipo que fuera, y por otro lado no supondrá que vaya a disminuir el empleo sino que éste será de otra forma.

Lo anterior podrá llevar a que las personas que trabajen en la planta lo harán en una planta virtual que podrá estar ubicada en su casa, una oficina, una biblioteca, una plaza pública, un aula de escuela o universidad, etc. La persona deberá de estar equipada con medios telemáticos adecuados, algunos de los cuales hoy pueden existir, otros pueden estar en fase de experimentación, otros en la mente creativa de alguna persona o equipo, y otros esperando a ser pensados. Lo que será vital es que la persona esté dotada de los medios y mandos telemáticos que la permitan interactuar con la máquina y las personas desde cualquier lugar y condición con la máxima 
ergonomía y sencillez y por supuesto con manos libres. Uno de estos ingenios podría ser algo así como "Glasses Mobile Computer-GMC" que dotarian a la persona de visión, audio y memoria instantánea y que al ser portados por los trabajadores les permitirian las interacciones necesarias para el trabajo, esté donde esté el punto de trabajo, a la vez que compartir los espacios con las personas que les estén ya próximas ya en cualquier lugar con la sensación de visión en 3D y sensación de cercanía, como si uno y los demás pudieran tocarse.

Claro está que los humanos tienen cinco sentidos así que puestos a soñar ¿por qué no dotarles de este tipo de ayudas, pero para los cinco sentidos? Tema importante porque aunque aprentemente pueda pasar desapercibido la aplicación de los 5 sentidos puede enriquecer la calidad y disfrute de gran número de trabajos. Si se avanzara en este campo, el GMC se podría transmutar en otro ingenio, el "nSMC" dónde " $n$ " es el número de sentidos incorporados y "S" Sentidos y MC como antes. Con ellos el GMC pasaria a ser 2SMC o "two Sense Mobile Computer", si se incorporara el olfato tendriamos 3SMC y así hasta 5SMC o "five Sense Mobile Computer".

Con estos medios, la persona ya estará equipada para trabajar y lo podrá hacer desde cualquier lugar. La cuestión es desde dónde, será cuestión de optimizaciones, así si el trabajador quiere hacerlo desde casa que lo haga, pero habrá que ver como afecta ello a la socialización y el mestizaje que siendo hoy muy importantes lo serán cada vez más. Si la cuestión fuera que en casa la persona ni se socializa ni mestiza, tendrá que salir, pero no para estar horas en trenes, autobuses, atascos, etc., sino para dedicar el tiempo de trabajo a crear valor, así que se irá a unos centros locales, que pudieran existir en cada barrio, escuela, centro deportivo, parroquia, universidades, áreas de aparcamiento colectivo, bibliotecas, ludotecas, plaza del barrio..., etc., centros a los que acudirán personas que trabajen en otras empresas y que desde allí atenderán sus instalaciones. Estos centros pudieran llamarse "ágoras del emotalento". En estas ágoras del emotalento las personas intercambiarían sus experiencias, conocerían otras formas de trabajar, se enriquecerían unas a otras y ahorrarian mucho tiempo, energía y dinero en desplazamientos que les permitirian conciliar su vida privada con la de la empresa a la vez que ayudar de forma notable a la reducción de las emisiones de $\mathrm{CO}_{2}$ y $\mathrm{NO}_{x}$. Por supuesto que esta forma de trabajar no deberá de sustituir, al menos al inicio, a la del trabajo presencial en su totali- dad ya que habrá que buscar las fórmulas que permitan el contacto personal entre los trabajadores con la frecuencia necesaria en cada caso, frecuencia que irá determinada por el aprendizaje en el uso y disfrute de los equipos "nSMC".

De esta forma los "Trabajadores del emotalento" priorizarán, y como consecuencia de ello sus empresas también, aspectos relacionados con la calidad de vida en el entorno social en el que residan y por extensión en el resto de la sociedad, siendo una derivada de ello el cambio del paradigma de la globalización actual, con centros de producción o de aprovisionamiento de materias primas ubicados en cualquier lugar del globo desarrollada sobre la priorización del coste para pasar a una visión holística en la que además del coste se incluyan aspectos como los de Responsabilidad Social y Sostenibilidad. Es posible que el cambio de paradigma de bases de decisión llevará a optar por centros de producción regionales con empleo de materias primas regionales localizados razonablemente cerca de los centros de consumo, reduciendo de manera significativa los costes de logística, costes que hoy por hoy son de los más importantes en términos de generación de gases con efecto invernadero y del agotamiento de las reservas naturales de combustibles fósiles. De alguna forma esta idea significa la recuperación del concepto Regionalización versus Globalización en el marco de algo que se podría llamar de Post Globalización que en un ejercicio de movimiento pendular permite retornar a los orígenes previos a la caída del Muro de Berlín, pero con un nuevo bagaje en la mochila que no es otro que lo aprendido en dos décadas largas de globalización desenfrenada.

Como consecuencia de ello es posible que el concepto de "fábricas de mundo" que hoy se ha desarrollado ampliamente en y con los países emergentes en unos casos y en otros en los paises del primer mundo para algunos productos muy especiales, tenga sus días (años) contados, lo que de ser así significará un impacto social impresionante, ya que beneficiará a los países del llamado primer mundo, al reiniciar un nuevo camino de la reindustrialización sobre la base de una más que notable mejora de la eficiencia energética, mientras que obligará a reenfocar el camino del desarrollo y accesibilidad a los niveles de calidad de vida del llamado primer mundo a los paises emergentes.

Tema complejo donde los haya en cuya solución será fundamental el llamado emotalento. 
Ésta sería una buena misión y visión de la empresa extendida y sostenible, ya que si a esta previsible situación no se le encuentra una solución justa, pero justa en términos de Justicia entre iguales, sobrevendría una situación global altamente inestable y de alto riesgo. Dicho de otra manera, es posible que llegue el día, y que éste esté próximo, en el que los coches ya no lleven materias primas o componentes originarios de cualquier lugar de los cinco continentes porque son más competitivos en coste sino que más bien las llevarán de regiones o subregiones de un continente determinado y se venderán en esas regiones o subregiones de forma que a medida que el peso de la Sostenibilidad aumente el peso de las subregiones le seguirá. Algo similar ocurrirá con y en la industria de la vestimenta o la del cazado o la de la línea blanca, en definitiva en todos los productos de consumo.

En igual medida esta nueva cultura afectará a las empresas que se han diseñado como centro de fabricación único con alcance global, lo que ocurre con frecuencia en el contexto empresarial del llamado primer mundo para bienes y productos cuya demanda no es masiva, que ahora deberían de regionalizarlos con el consiguiente beneficio para los paises más lejanos, incluidos aquéllos que hoy pudieran no estar favorecidos en las actividades manufactureras por la causa que fuere. De esta última acción podrán quedar exentos los casos en los que la demanda sea muy escasa o irregular y que por sí misma no justifique la inversión en términos, ya sea de formación de las personas o capital a invertir o equilibrio de sostenibilidad en la inversión o de responsabilidad social.

Es muy posible lo único que quedará con alcance global sea el emotalento de las personas, ese intangible de los conocimientos, aptitudes y actitudes que al no consumir energía no genera subproductos que dañen el medio ambiente.

La Post Globalización vendrá acompañada de un cambio notable en el entendimiento de la ecuación del Beneficio. Ecuación que ahora se reduce a "Beneficio=resultado Financiero <> B=F", cambio que no será fácil, entre otras cosas porque la base del "B = F" es la moneda así como el valor y cuantificación del intercambio, temas que están en la cultura humana desde los inicios de la época agrícola, más o menos hace unos 8.000 años, lo que ha creado unos memes difíciles de modificar en el corto plazo de una o dos generaciones, pero no imposibles si la estuación de valor cambia y se explica bien. La propuesta que desde aquí se hace es que la ecuación de la economía de las empresas pasará de ser "B = F" o "Beneficio igual a resultado Financiero" a:

$$
\text { "B }=\mathrm{a} * \mathrm{~F}+\mathrm{b} * \mathrm{~S}+\mathrm{c} * \mathrm{RS} "
$$

donde:

$-a$, b y c son constantes variables en función de la cultura de la época cuya suma es la unidad. En nuestros días "a" es 1 y "b" y "c" son cero. Por ello "B = F".

- F es el resultado financiero de la empresa.

- S es el resultado de Sostenibilidad.

- RS es el resultado de Responsabilidad Social.

La incógnita sobre la que especular ahora es la de cuál va ser el peso de "b" y "c". Lo que con toda certeza sí se puede predecir es que será mayor que cero. Si la propuesta cuajara habría que esperar una reacción del gran capital financiero que propondría la contra pregunta: ipuesto que la ecuación tiene su origen en la sostenibilidad, qué ocurriría si ante la presión de una medida así el mundo empresarial reaccionara consiguiendo un sistema global y regional de logística que tenga la doble función de: 1) la fuente de energía es renovable, y 2) no auto contiene subproductos que lesionen el medio ambiente, ni la salud, ni la calidad de vida?

Pregunta cuya respuesta más razonable pudiera ser: "Que sería excelente, aunque muy poco probable en las próximas décadas, en cuyo caso, y especialmente si el medio energético puesto a disposición de la sociedad es barato, la globalización volvería y con más fuerza quizá ya que estaría gobernada por el aspecto económico, salvo que emergiesen otros factores al amparo de la Responsabilidad Social de las empresas que tuviesen peso suficiente para mantener la Regionalización, factores que los hay y habrá, vista la cada vez mayor brecha entre unos y otros a la que hemos llegado con la Globalización".

La Post Globalización entendida como aquí de describe se puede sintetizar en un acrónimo que va un poco más allá del 3l+D (Internacionalización, Investigación, innovación + Desarrollo) que es una evolución del I+D+i de los últimos años, el acrónimo propuesto es: 3IDRS2 (11) o lo que es lo mismo:

(Internacionalización, Investigación, innovación + + Desarrollo + Responsabilidad Social y Sostenibilidad) 


\section{Conclusiones}

La empresa y la sociedad tienen innumerables campos de interacción, muchos de ellos tejidos por el hilo de la innovación. Uno, en el que la sociedad puede ayudar mucho a la empresa es el de poner una parte notable de su energía en la conservación en Europa del tejido empresarias e industrial vinculado con las transformaciones de los productos centenarios y milenarios, no haciendo de este Continente Europeo un desierto industrial y empresarial que pueda ser necesario en próximas generaciones de Post Globalización.

\section{AGRADECIMIENTOS}

Recibido: 29 de junio de 2010

Aceptado: 31 de octubre de 2010
Deseo dar las gracias a:

1. Ander Gurrutxaga por haberme invitado a poner en negro sobre blanco lo que pienso sobre la empresa y su relación con la innovación social.

2. Cristina Ugalde, Onintze Matías y Tomás López, asi como al equipo Pegasus de Vicinay Cadenas por haber leído, corregido y realizado importantes sugerencias que han mejorado de forma notable esta reflexión.

Darwin, C. (2008): El origen de las especies, Madrid: Espasa Calpe.

Documentación de Vicinay Cadenas S.A.

Galison, P. (2005): Relojes de Einstein, mapas de Poincaré. Los imperios del tiempo, Barcelona: Crítica.

Machado, A. "Campos de Castilla (19071917)", poema XXIX en Proverbios y Cantares, Edición Manuel Alvar.

OCDE (2005): Manual de Oslo. Guía para la recogida e interpretación de datos sobre innovación, Tragsa.

Popper, K. (2006): La sociedad abierta y sus enemigos, Barcelona: Paidós.

Rifkin, J. (2010): La civilización empática. La carrera hacia una conciencia global en un mundo de crisis, Barcelona: Paidós.

\section{BIBLIOGRAFÍA}

Anónimo: La Biblia, Génesis, 3.

Ayala, F. J. y Cela Conde, C. J. (2006): La piedra que se volvió palabra. Las claves evolutivas de la humanidad, Madrid: Alianza Editorial.
Wittgenstein, L. (2007): Tractatus logico philosophicus, Madrid: Tecnos.

Después de escuchar al Viceconsejero Juan Goikolea la expresión "3I+D", quien a su vez la pone como referencia del Lehendakari López, Faro Intergune, Cámara Comercio Guipúzcoa. 